\section{Investing in universal health in the Americas}

\author{
Carissa F. Etienne ${ }^{1}$
}

Suggested citation Etienne CF. Investing in universal health in the Americas. Rev Panam Salud Publica. 2018;42:e90. https://doi.org/ 10.26633/RPSP.2018.90

\section{THE CHALLENGE}

Investing in health is a whole-of-society commitment and a requirement for sustainable development. The links between health, development and economic growth have been well established with abundant evidence that demonstrates the benefits of increased health investment for sustainable human development, economic growth and population well-being. Evidence also reveals that better health outcomes and healthier populations contribute to higher productivity and therefore better economic results. (1-4)

The reality in the Region of the Americas remains challenging in this regard. Health systems are under-funded and characterized by segmentation and fragmentation in financing and service provision, with inefficiencies in the allocation and use of limited resources. These problems result in poorer health outcomes and contribute to persistent poverty and inequities, with the greatest impact on populations in conditions of vulnerability. The way forward then is two-fold: find new public sources of funding while simultaneously increasing efficiency in health systems financing and health services organization to better respond to population needs.

\section{THE FRAMEWORK}

The Pan American Health Organization (PAHO)'s strategy for universal access to health and universal health coverage ("universal health" strategy) adheres to the values of equity, solidarity and the right to health and provides a regional framework for ensuring "health for everyone, everywhere." This strategy recognizes the need to raise the level of public expenditure on health to at least $6 \%$ of GDP as a necessary, but not sufficient, condition to reduce inequities and increase financial protection by eliminating direct payments at the point of service. (5) This in turn requires the creation of fiscal space for health investment by generating additional resources, a requisite for making the transformations needed to improve efficiency, expand access to quality health services and protect the population from out-ofpocket expenditures that lead to impoverishment.

The task, however, is not simple. The majority of countries in the Americas fall far short of this $6 \%$ benchmark. In 2015, public expenditure in health averaged close to $4 \%$ of GDP region-wide, and only five of thirty-four countries had public spending levels above the benchmark. Only in four countries does the public component exceed $70 \%$ of total health expenditure, and only six present a level of direct payments below $20 \%$ of total health expenditure, the level at which the incidence of financial catastrophe and impoverishment becomes negligible. (6)

On the other hand, we know well that in the Americas, the hospital-centric (biomedical) model of care overwhelmingly drives health investment. Funds are usually channeled preferentially to create infrastructure at the specialized levels, negatively impacting the health system's capacity to efficiently meet the population's needs. For example, data from the Caribbean indicate that in 2014, at least 36831 deaths from non-communicable diseases were considered "avoidable" (representing $83.8 \%$ of all avoidable deaths) because they occurred in people under age 50. These deaths could, potentially, have been avoided if health systems offered quality and timely access to prevention at all levels of health care services (primary and specialized). (7)

CC This is an open access article distributed under the terms of the Creative Commons Attribution-NonCommercial-NoDerivs 3.0 IGO License, which permits use, distribution, and reproduction in any medium, provided the original work is properly cited. No modifications or commercial use of this article are permitted. In any reproduction of this article there should not be any suggestion that PAHO or this article endorse any specific organization or products. The use of the PAHO logo is not permitted. This notice should be preserved along with the article's original URL. 


\section{OPTIONS}

The challenges to transforming this reality can seem overwhelming or impossible to achieve, especially within a context of global uncertainty, with some countries facing sluggish economic growth prospects, high levels of government debt, political and social instability, and vulnerability to the unpredictable ravages of natural disasters and disease outbreaks. According to the International Monetary Fund, economic growth in Latin America and the Caribbean during 2016 was the third lowest in 30 years, as a result of ongoing fiscal and external adjustments in some countries and other country-specific factors. Over the medium term, the projections show that growth is likely to remain constrained at $2.6 \%$, after expanding $1.1 \%$ in 2017 and $2 \%$ in 2018. (8)

Clearly in this context, the Region cannot rely solely on growth to protect and sustain the enormous social gains and reductions in inequality that have been achieved over the past 15 years. Instead, the challenge will be to increase investment in people, particularly the poor, despite these trends, using countercyclical policy frameworks to ensure sustainable and equitable long-term growth. (9)

Indeed the message from the articles included in this thematic series is that even during difficult times and economic stagnation, it is possible to increase public investment in health. PAHO, as part of its commitment to universal health, has developed a framework to help countries identify and utilize existing fiscal space for health. Increased public resources can come from a wide range of sources, including improved tax collection (by reducing evasion and elusion), new or increased public health taxes, reduced waste and corruption and increased efficiency, the prioritization of expenditure in health over other sectors, social contributions, and more. Every country can do something according to its national context.

\section{INVESTING WISELY}

We know from the experience of some countries that higher levels of health expenditure do not necessarily translate into better health outcomes. Thus, when we advocate for increased availability of public resources for health, we should not forget that those additional resources must be used wisely. To advance toward universal health, resource allocation should be aimed at increasing equity by prioritizing the first level of care, seeking to improve its response capacity and moving decisively to develop integrated health service delivery networks.

\section{CALL FOR ACTION}

It is time for decision makers to progress from evidence to action. Increasing priority for health in the use of government resources is an imperative, which cannot be accomplished without political will. I have no doubt that future generations will be grateful for our efforts to increase investments in health systems to make them stronger, more resilient and more inclusive, as this will also contribute to stronger, more productive and more inclusive societies.

It is with the aim of contributing evidence and options towards the goal of increasing priority for health that the Pan American Journal of Public Health is publishing this thematic series entitled "Financing and fiscal space for universal health in the Americas." The series includes articles on the relationship between public expenditure in health and economic growth in the Americas, trends on public expenditure in health and specific options in individual countries (Bolivia, Honduras and Peru), tobacco taxation in the Caribbean sub-region, and the role of National Health Accounts in countries' decision-making processes, among others. The evidence presented in this series is intended to open the door for discussion on how to address the challenges currently facing health systems financing using an innovative approach. 


\section{REFERENCES}

1. World Health Organization. Macroeconomics and health: investing in health for economic development. Report of the Commission on Macroeconomics and Health. Geneva: WHO; 2001. Available from: http://apps.who.int/iris/bitstream/10665/42435/1/924154550X. pdf. Accessed on May 12018.

2. Jamison DT, Summers LH, Alleyne G, Arrow KJ. Global health 2035: a world converging within a generation. Lancet 2013;382(9908):1898-1955.

3. World Bank. World Development Report 1993: Investing in Health. New York: Oxford University Press; 1993. Available from: https://openknowledge.worldbank.org/ handle/10986/5976. Accessed on May 12018.

4. Barro R. Determinants of economic growth: a cross-country empirical study. Cambridge: MIT Press; 1998.

5. Pan American Health Organization. Strategy for Universal Access to Health and Universal Health Coverage (CD53/5. Rev.2). Washington: PAHO; 2014. Available from: http:// www.paho.org/uhexchange/index.php/en/uhexchange-documents/technicalinformation/26-strategy-for-universal-access-to-health-and-universal-health-coverage / file. Accessed on May 12018.

6. World Health Organization. The World Health Report 2010. Health Systems Financing. The path to universal coverage. Geneva: WHO; 2010. Available from: http:/ /www.who. int/whr/2010/en/. Accessed on May 12018.

7. PAHO health information Platform for the Americas (PLISA). Database. Data retrieved in March 2017.

8. International Monetary Fund. Regional Economic Outlook. Western Hemisphere. Tale of two adjustments. Washington DC: IMF; 2017. Available from: https://www.imf.org/en/ Publications/REO/WH/Issues/2017/05/10/wreo0517) Accessed on May 12018.

9. The World Bank and Latin America and The Caribbean. Overview. Washington DC World Bank; 2017. Available from: http://www.worldbank.org/en/region/lac/overview Accessed on May 12018. 